\title{
The use of multi-criteria optimization to choose solutions for energy-efficient buildings
}

\author{
M. BASIŃSKA* \\ Poznan University of Technology, Faculty of Civil and Environmental Engineering, Institute of Environmental Engineering, \\ 4 Berdychowo St., 60-965 Poznan, Poland
}

\begin{abstract}
The goal of this paper was to optimize the building envelope and technical equipment in the building through the mitigation of the global cost value, and then to evaluate the influence of the chosen assumptions on the primary energy index. The analyses carried out using global cost method allow for finding the cost optimal solution but only for the some range of primary energy index variability. In order to find the optimal solutions it was proposed to use the multi-criteria optimisation, assuming the following as basic criteria: a global cost value and investment prices increase (economic criteria), a primary energy index (energy-related criterion), an emission of carbon dioxide (environmental criterion). The analysed case study refers to the technical solutions for the residential buildings with the usable energy demand at the level of 40 and $15 \mathrm{kWh} / \mathrm{m}^{2} / \mathrm{a}$. The presented method might be applied to different types of buildings: those being designed and those being the subject of the thermo-modernisation. The results demonstrate that the proposed model allows for classification of the alternative technical solutions regarding the designing process and the building's technical equipment. The carried out analyses indicate the economic possibility to achieve the low energy building standard and show the need to concentrate the activities related to the installation technology and used energy source.
\end{abstract}

Key words: global cost methodology, low energy buildings, European Union Directive, multi-criteria optimization.

\section{Introduction}

According to the enacted changes to the EU Directive (EPBD) [1], starting from 2021 all newly built objects in European Union have to fulfil the criteria of the buildings with 'close to zero' energy demand. The requirements of the Directive were implemented in Poland in 2008 and applying its decisions the new requirements regarding the building's heat protection were introduced. The Building Law [2] defines the general requirements regarding the rational usage of the energy in the buildings, while the constituted implementing act (IA) [3] defines, amongst the other, the particular requirements regarding: volume of the permissible index of the primary energy for the building, the thermal insulation of the building's components and also the requirements regarding the mechanical systems of the building's equipment.

According to IA, the process of achieving the zero-energy standard in the building industry will proceed gradually. The Polish government aims at reducing the primary energy use, per heated building area in relation to the requirements of 2017, by $26 \%$ for one-family building and $24 \%$ for multi-family building in 2021 [3]. It was assumed that the activities within the area of the building cannot include, only and exclusively, the construction improvements, but the particular attention should be

*e-mail: malgorzata.basinska@put.poznan.pl

Manuscript submitted 2017-02-01, revised 2017-05-10, initially accepted for publication 2017-06-22, published in December 2017. focused on the applied mechanical systems in the scope of heating, ventilation, air conditioning (HVAC) and the sources of the energy supplying the building. The goal of these activities is to re-shape the building and its technical equipment in such a way to limit the energy usage. As a result it should lead to the limitation of $\mathrm{CO}_{2}$ emission.

The basic aim of this paper is to present the method of the economic, energy-related and ecological evaluation of the building and its mechanical equipment. The main goal of this paper was to optimize the building's envelope and its technical equipment. The problem of the multi-criteria optimization was solved, including the minimalisation of the global cost, primary energy index, emission of carbon dioxide and the increase of the investment costs in relation to the basic scenario. The options of the possible technological activities aiming for achieving the standards of the low-energy building were compared and then the best solution for the Polish economic conditions was indicated. The analyses referred to the building components, creating the building's envelope as well as to the components of the mechanical systems (HVAC) and the energy sources supplying the building's technical systems. The primary aim was to provide a comparison of the proposed solutions with the basic scenario (BASE).

The proposed method was used to indicate the integrated activities (construction technology, mechanical system, energy sources) aiming for the improvement of the technology - related quality in the residential buildings in terms of the sustainable development, assuming at the same time, the variability of the initial data by means of building's decomposition for the frag- 
mentary building's components forming the envelope and the elements of the mechanical system - HVAC - or the energy sources supplying the building.

The paper is divided into the following parts: Section 2 presents the concept of energy-related and economic evaluation model and the evaluation criteria of the technical solution used in the building. Section 3 presents the description of the analysed buildings and the summary of the analysed options divided into 3 parts: building envelope (BE), mechanical system in the terms of HVAC (HVAC) and the energy sources supplying the building (ES). Section 4 presents the results of the calculations done according to the algorithm presented in Section 2, multi-criteria analysis. The uniform framework of the procedures for a different analysed solutions were applied in order to choose the optimal solution.

\section{Methodology}

The monthly method of calculation of energy use for space heating and cooling, in accordance with PN EN ISO 13790 [4], was used for evaluation of the construction solutions, mechanical systems in terms of HVAC and the energy sources supplying the building dedicated for low energy building industry. Two energy standards for the building were the subject of the analysis: low energy building (LEB) - usable energy at the level of $\mathrm{UE}=40 \mathrm{kWh} / \mathrm{m}^{2} / \mathrm{a}\left(\mathrm{UE}_{40}\right)$ and very low energy building (VLEB) - usable energy at the level $\mathrm{UE}=15 \mathrm{kWh} / \mathrm{m}^{2} / \mathrm{a}\left(\mathrm{UE}_{15}\right)$. The analyses were done for the statistic heating season [5].

Increase of the energy prices was assumed according to the estimation presented in European Union report for the period of time up to 2050 [6]. The energy costs were estimated based on the data provided by Energy Regulatory Office [7], assuming the net cost of the energy in case of electricity at the level 0.46 PLN $/ \mathrm{kWh}$ and gas $-0.16 \mathrm{PLN} / \mathrm{kWh}$. The cost of the energy getting from pellet $(0.14 \mathrm{PLN} / \mathrm{kWh})$ was estimated according to the current market costs, while district heating costs was assumed according to the tariff given by Veolia Polska [8]. Economic analysis of the recommended by the International Organisation for Standardization (ISO) [9] conventional systems was extended by the possibility to choose the renewable sources of energy (RES). For each of the analysed energy carrier, following the recommendation of Institute of Environmental Protection and National Research Institute (IOS-PIB) [10] the factor of carbon dioxide emission was assumed, respectively, for gas $-56 \mathrm{MgCO}_{2} / \mathrm{TJ}$ and for bio-mass $-112 \mathrm{MgCO}_{2} / \mathrm{TJ}$. The values for the electricity are at the level of $0.823 \mathrm{MgCO}_{2} / \mathrm{MWh}$ [11], and for Poznan district heating - 0.219 $\mathrm{MgCO}_{2} / \mathrm{MWh}$ [8]. It was assumed the cost of carbon dioxide emissions at the level of 20 Euro/ $\mathrm{MgCO}_{2}\left(88 \mathrm{PLN} / \mathrm{MgCO}_{2}\right)$. The calculations assume the low temperature condensing gas boiler as reference source due to the fact that usage of a gas as energy source increases in Poland and also the effectiveness of such solution has improved significantly over the years.

The proposed integrated activities were compared in the terms of their profitability in PLN/m². The initial costs of the investment and maintenance cost were assumed based on the analysis of costs known from the consumer market. In case of costs of replacing, the assumed lifespan was 40 years for thermal insulation, 30 years for the windows and 15 years for all elements of the technical equipment in the building as well as 20 years for renewable energy sources (RES).

In the analyses of the costs, for the residential building within 30 years period, the discount rate was taken into consideration - at the level of $0.5 \%$ - as well as the value of money in the interbank trading (yearly WIBOR) at the level of $1.80 \%$.

For the purpose of analyses the multi-criteria optimization method was applied - so called weighted sum method - taking into account the objective variants $C_{r}$ - the criteria $(r=4)$. Following the description of the factors influencing the energy-related evaluation of the building they are listed as follows: $\mathrm{C}_{1}$ - an energy criterion, $(\mathbf{P E}), \mathrm{C}_{2}$ - environmental criterion, $\left(\mathbf{C O}_{2}\right), \mathrm{C}_{3}$ - economy criterion, $\left(\mathbf{C}_{\mathbf{G}}\right)$ and $\mathrm{C}_{4}$ - investment costs return criterion, $\left(\Delta \mathbf{C}_{\mathbf{i n}, \text { inv }}\right)$ [12-19]. The goal of the method is to choose the compromise solution from all available solutions (equation 1)

$$
\begin{aligned}
\text { Maximum: } F= & \rightarrow \boldsymbol{f}(\rightarrow \boldsymbol{y})=\left[f_{1}(\rightarrow \boldsymbol{y}), f_{2}(\rightarrow \boldsymbol{y}),\right. \\
& \left.f_{3}(\boldsymbol{\rightarrow} \boldsymbol{y}), f_{4}(\rightarrow \boldsymbol{y})\right]
\end{aligned}
$$

In order to normalize the criteria the inhibitor was applied to the variants matrix, which means: the lower value of the given criterion, the higher grate achieved by the given variant. For appointing the optimal solution the aggregated indicator of $y$ variant was applied.

$$
\begin{array}{r}
\boldsymbol{y}=\rightarrow \boldsymbol{f}\left(\rightarrow \boldsymbol{X}, w_{h t}\right)=[ \\
{\left[f_{1}\left(\rightarrow \boldsymbol{X}, w_{h t}\right), f_{2}\left(\rightarrow \boldsymbol{X}, w_{h t}\right),\right.} \\
\left.f_{3}\left(\rightarrow \boldsymbol{X}, w_{h t}\right), f_{4}\left(\rightarrow \boldsymbol{X}, w_{h t}\right)\right]
\end{array}
$$

where: $\rightarrow \mathbf{y}-$ vector of variant's aggregated indicator $\rightarrow \mathbf{x}$; $\mathrm{W}_{\mathrm{ht}}-$ criterion weight; $\rightarrow \mathbf{X}$-vector of the normalized value of $\mathrm{C}$ criterion for the variant $\rightarrow \mathbf{x}$ consistent with the dependency (3).

$$
\begin{array}{r}
\boldsymbol{X}=\rightarrow \boldsymbol{f}(\rightarrow \boldsymbol{x})=\left[f_{1}(\rightarrow \boldsymbol{x}), f_{2}(\rightarrow \boldsymbol{x}),\right. \\
\left.f_{3}(\rightarrow \boldsymbol{x}), f_{4}(\rightarrow \boldsymbol{x})\right]
\end{array}
$$

Within each of the criteria the problem of optimisation lies in the minimization of the final value in accordance with the below description.

$$
\begin{gathered}
\text { Minimize: } \boldsymbol{C}=\rightarrow \boldsymbol{f}(\rightarrow \boldsymbol{x}) \\
\rightarrow \boldsymbol{x}=\left[x_{1}, \ldots, x_{n}\right]
\end{gathered}
$$

where: $\rightarrow \mathbf{x}$ - vector of $\mathrm{n}$ decision variables.

Each element of the vector $\rightarrow \mathbf{x}$ corresponds with the decision variant i.e. defines the costs and the appropriate technical parameters connected to the given variant. The variant $\rightarrow \mathbf{x}$ is a combination of the variable activities in terms of building's 
envelope, mechanical systems (HVAC) and used in the building energy source.

2.1. Energy-related criterion - primary energy, $(\mathrm{PE})$. The primary energy estimation was done according to the stipulations of the ordinance regarding the building's energy characteristic [20]. The method includes the primary, final and usable energy. The calculations were carried out according to the flow chart presented by Basińska et al. in paper [21]. The criterion can be described by the value of primary energy index pointed for the given technical solution $\rightarrow \mathbf{x}$ and to define as an annual usage of the energy calculated for the building's heated area unit according to equation (6). It includes the final energy value at the balance boundary of the building and the disbursals of the non-renewable primary energy for a delivery of the used energy carrier to the boundary of the object. The value of the primary energy includes the demands for heating and ventilation and preparation of the domestic hot water (DHW). The analysis does not include the cooling option. The air quality was considered by means of the application of the data regarding exploitation indoor temperature and the resultative airflow as the input for calculation of the energy cost and values of the global costs.

The following tags were used in equation (6): PE, primary energy ratio, $\mathrm{kWh} / \mathrm{m}^{2} / \mathrm{a} ; \mathrm{Q}_{\mathrm{i} \text {, nd }}$, the building energy demand, $(\mathrm{i}=\mathrm{H}-$ for space heating and ventilation, $\mathrm{i}=\mathrm{W}-$ for domestic hot water preparation) $\mathrm{kWh} / \mathrm{a} ; \mathrm{E}_{\mathrm{el}, \text { aux }}$, the annual demand for final electric energy to drive the auxiliary devices of the given system, $\mathrm{kWh} / \mathrm{a} ; \mathrm{f}_{\mathrm{i}, \mathrm{k}}$, the percentage of the energy demands provided by i system; $\mathrm{w}$, the expenditure coefficient of non-renewable primary energy to generate and supply the final energy carrier (or energy) to the evaluated building, which is determined by the energy or energy carrier supplier $\left(\mathrm{w}_{\mathrm{el}}-\right.$ for electricity, $\mathrm{w}_{\mathrm{H}}-$ for heating and ventilation, $\mathrm{w}_{\mathrm{w}}-$ for domestic hot water preparation; $A_{f}$, heated net floor area, $\mathrm{m}^{2}$; $i$, the index of the system; $\eta_{i, \text { tot }}-$ the total efficiency of the system including: regulation losses, distribution, storage, and generation.

The value of the usable energy depends on the designing parameters related to the building, the total efficiency - from the applied solution for mechanical system - HVAC, the expenditure coefficient of non-renewable primary energy necessary for the generating and supply of the energy carrier to the building - from the energy carrier chosen for the given building.

2.2. Environmental criterion, $\left(\mathbf{C O}_{2}\right)$. The environmental criterion refers to the carbon dioxide emission generated by the construction site and exploitation of HVAC system.

The analyses did not take into account $\mathrm{CO}_{2}$ emissions from the production of building and installation materials. The emission is calculated based on the final energy consumption according to dependency (7), where $\mathrm{W}_{\mathrm{e}, \mathrm{i}}$ means $\mathrm{CO}_{2}$ emission indicator depends on the type of the burnt fuel by i system, $\mathrm{MgCO}_{2} / \mathrm{TJ}$. The remaining tags were used just like in equation (6).

2.3. Economic criterion $-\mathbf{C}_{\mathbf{G}}$. In accordance with the European Directive [1] in order to evaluate the building energy effi- ciency the global cost method was applied [9]. This method includes the indication of the total global cost within the assumed calculation period (for the residential building $\tau=30$ years), that global cost is a sum of the investment initial costs and the discounted annual costs of the exploitation.

In the macro-economic calculations the investment net costs are taken into consideration (not including the due taxes and subsidies) and the costs connected to the carbon dioxide emission (understood as the monetary value of a detriment caused to the environment via emission of $\mathrm{CO}_{2}$ related to usage of the energy by the energy source in the building). Economic criterion can be described by the dependency (8).

$$
\begin{aligned}
& \rightarrow C_{1}(\rightarrow \boldsymbol{x})=P E(\rightarrow \boldsymbol{x}) \\
& =\left[\sum_{k=0}^{k_{H}} \frac{f_{H, k} \cdot Q_{H, n d}(x)}{\eta_{H, t o t}(x)} \cdot \frac{w_{H}(x)}{A_{f}}\right]+ \\
& =\left[\sum_{k=0}^{k_{W}} \frac{f_{W, k} \cdot Q_{W, n d}(x)}{\eta_{W, t o t}(x)} \cdot \frac{w_{W}(x)}{A_{f}}\right]+ \\
& =\left[\sum_{k=0}^{k} f_{H+W, k} \cdot E_{e l, a u x}(x) \cdot \frac{w_{e l}(x)}{A_{f}}\right] \\
& \rightarrow C_{2}(\rightarrow \boldsymbol{x})=\mathrm{CO}_{2}(\rightarrow \boldsymbol{x}) \\
& =\left[\sum_{k=0}^{k_{H}} \frac{f_{H, k} \cdot Q_{H, n d}(x)}{\eta_{H, t o t}(x)} \cdot \frac{w_{e, H}(x)}{A_{f}}\right]+ \\
& =\left[\sum_{k=0}^{k_{W}} \frac{f_{W, k} \cdot Q_{W, n d}(x)}{\eta_{W, t o t}(x)} \cdot \frac{w_{e, W}(x)}{A_{f}}\right]+ \\
& =\left[\sum_{k=0}^{k} f_{H+W, k} \cdot E_{e l, a u x}(x) \cdot \frac{w_{e, e l}(x)}{A_{f}}\right] \\
& \rightarrow C_{3}(\rightarrow \boldsymbol{x}, \tau)=C_{G}(\rightarrow \boldsymbol{x}, \tau)=C_{i n, i n v}(\rightarrow \boldsymbol{x})+ \\
& +\sum_{j=1}^{j_{x}}\left[\sum_{i=1}^{\tau}\left(C_{a, i}(j)(\rightarrow \boldsymbol{x}, \tau) \cdot R_{d}(i)\right)-V_{f, \tau}(j)(\rightarrow \boldsymbol{x}, \tau)\right. \\
& V_{f, \tau}(j)=C_{i n, i n v}(j) \cdot\left(1+\frac{R_{p}}{100}\right)^{n_{\tau}(j) \cdot \tau_{n}(j)} . \\
& \cdot\left[\frac{\left.\left(n_{\tau}(j)+1\right) \cdot \tau_{n}(j)-\tau\right)}{\tau_{n}(j)}\right] \cdot R_{d}(\tau)
\end{aligned}
$$

In equation (8) the following tags were used: $\mathrm{C}_{\mathrm{G}}$, global cost referred to the starting year, $\mathrm{PLN} / \mathrm{m}^{2} ; \mathrm{C}_{\text {in, inv }}$, initial investment costs, PLN $/ \mathrm{m}^{2} ; \mathrm{j}$, index of component or system, $-; \mathrm{j}_{\mathrm{x}}$, number of components or systems, $-; \tau$, calculation period, $\mathrm{a} ; \mathrm{C}_{\mathrm{a}, \mathrm{i}}(\mathrm{j})$, annual costs for component or system $\mathrm{j}$ of the year $\mathrm{i}, \mathrm{PLN} / \mathrm{m}^{2}$; $R_{d}(i)$, discount rate (for year $\left.i\right),-; V_{f, \tau}(j)$, final value of component or system $\mathrm{j}$ (corresponding to calculation period $\tau$ ); in other words the residual value of a measure or set of measures at the end of the calculation period (with respect to the initial 
year), PLN $/ \mathrm{m}^{2}$ according to equation 9 where additional: $\mathrm{R}_{\mathrm{p}}$, the rate of development of the price for products, $-; n_{\tau}(j)$, the total number of replacements of components $\mathrm{j}$ throughout the calculation period, -; $\mathrm{R}_{\mathrm{d}}(\tau)$, discount rate at the end of calculation period, - .

The value of money in time $R_{d}(p)$ takes into account the annual inflation rate $\left(\mathrm{R}_{\mathrm{i}}\right)$ and Warsaw Interbank Offered Rate (WIBOR) (equations 10a, 10b)

$$
\begin{gathered}
R_{d}(p)=\left(\frac{1}{1+\frac{R_{R}}{100}}\right)^{p} \\
R_{R}=\frac{\text { WIBOR }-R_{i}}{1+\frac{R_{i}}{100}}
\end{gathered}
$$

In equations (10a, 10b) the following tags were used: $R_{d}(p)$, discount rate, $-; \mathrm{R}_{\mathrm{R}}$, real interest rate, $\% ; \mathrm{p}$, number of years of operation of the building measured from the year zero, -;WIBOR, Warsaw Interbank Offered Rate, $\%$; $\mathrm{R}_{\mathrm{i}}$, annual rate of inflation, $\%$.

2.4. Investment costs return criterion $-\Delta \mathbf{C}_{\mathrm{in} \text {, inv }}$. In order to establish the profits for the Investors resulting from the applied energy - related solutions $\mathrm{C}_{1}$ criterion was corrected by the value of the additional investments above the base level, the criterion of investment costs return $-\mathrm{C}_{4}$. The cost of the additional investment $\Delta \mathrm{C}_{\mathrm{in} \text {, inv }}(\rightarrow \mathrm{x}, \tau)$, during the calculation period, results clearly from $\mathrm{j}$ investment costs of the given technical solution $\rightarrow x, C_{a}(j)$, during the year $i$, reduced by the costs related to the achievement of the base solution $\mathrm{C}_{a, B A S E}(\mathrm{j})$. These values were discounted to the initial year $i=0$, according to the discount coefficient. The costs of the energy are not included in this criterion.

$$
\begin{aligned}
\rightarrow C_{4}(\rightarrow \boldsymbol{x}) & =\Delta C_{i n, i n v}(\rightarrow \boldsymbol{x})=C_{G}^{*}(\rightarrow \boldsymbol{x}, \tau)- \\
& -\Delta C_{G}^{*}(B A S E, \tau)
\end{aligned}
$$

where: $\Delta \mathrm{C}_{\mathrm{in}, \text { inv }}$, the cost of the additional investment referred to the starting year, PLN $/ \mathrm{m}^{2} ; \mathrm{C}_{\mathrm{G}}^{*}(\rightarrow \mathbf{x}, \tau)$, the global cost of the variant $\rightarrow \mathbf{x}$ not including the costs of energy, PLN $/ \mathrm{m}^{2}$; $\mathrm{C}_{\mathrm{G}}^{*}(\rightarrow \mathrm{BASE}, \tau)$, the global cost of the base variant without the energy costs, PLN $/ \mathrm{m}^{2}$.

\section{Case study}

The subject of the analysis are two residential buildings. First of them is a residential building for one-family BSC_1 with a heated net floor area of $164 \mathrm{~m}^{2}$, the other one is multi-family building, four-storey building, inhabited by 32 people with heated net floor area of $833 \mathrm{~m}^{2}-$ BSC_3. The building represents a typical medium-size multi-storey building in an urban context [21]. The calculations include the data regarding climate in Poznań [5].

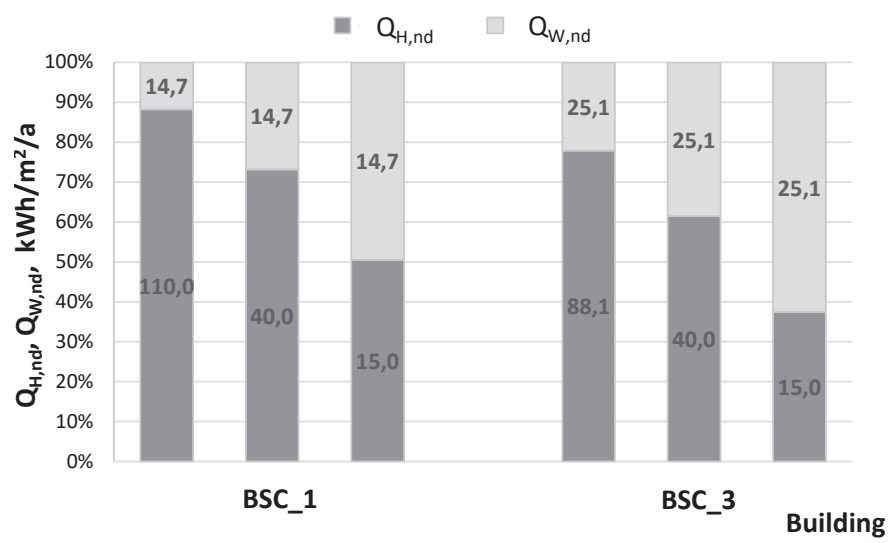

Fig. 1. The relation between the energy used for maintaining the comfort/ air quality parameters in the buildings and the energy necessary for hot water preparing

The Fig. 1 presents the relation between the energy used for maintaining the comfort/air quality parameters in the buildings and the energy necessary for hot water preparing.

The analyses consider, as the reference points for the chosen buildings, the thermal characteristic consistent with the thermal requirements valid till the end of 2016, according to [3] (a variant for the reference buildings described as BASE). The assumption is to use styrofoam as thermal insulation and the gas as an energy source. It is assumed that insulation is applied to the exterior facade, the roofing slab and the ground floor. The reference buildings (BASE) has double-glazed wooden framed windows with a solar heat gain coefficient $\mathrm{g}$ of 0.70 and a heat transfer coefficient $\mathrm{U}$ of $1.80 \mathrm{~W} / \mathrm{m}^{2} / \mathrm{K}$.

In the paper author has analysed the possibility to achieve two levels of the usable energy in the buildings to maintain the comfort and air quality parameters $-\mathrm{UE}_{40}$ and $\mathrm{UE}_{15}$. The proposed technical solutions are the package of the solutions combination in the terms of the building envelope, mechanical systems (HVAC) and applied energy source.

3.1. The analysed variants. The proposed multi-criteria analysis considers the choice of the compromise solution for each of the buildings. The variant $\rightarrow \mathrm{x}$ is a combination of the variable building activities (BE) -8 variants (Table 1), mechanical systems (HVAC) -3 variants (Table 2) and applied source of energy (ES) - 6 variants (Table 3), what gives initially 144 combinations for each of the analysed buildings and the levels of the usable energy. The analyses are taking under consideration the variants of the renewable energy systems (RES).

The number of the possible combination is unlimited and every time it can be enlarged by adding the new thermo-insulation materials or considering the combination of the energy sources. Set of the solutions is a description of the possible activities. An improvement of the objective value of function (according to equation 1) can be achieved only by assuming the degradation of the other goal's function. The above means that the chosen solution will enforce the compromise between the indicated goals in order to find the compromise solution. 
Table 1

Analysed variants of the building envelope responsible for energy usage - BE

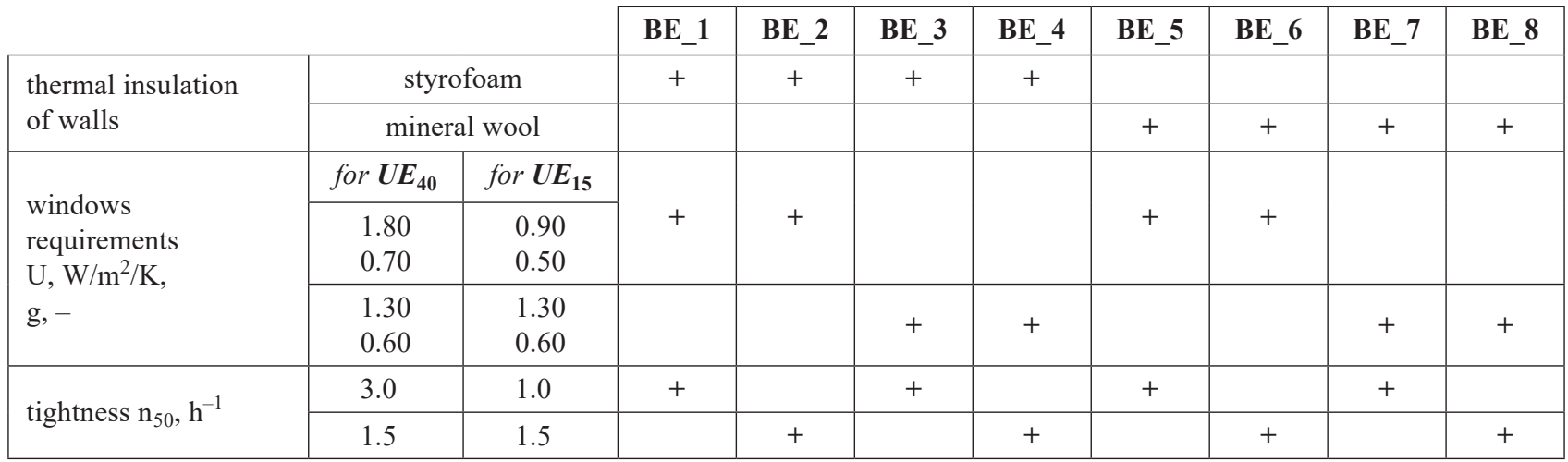

Table 2

Analysed variants of the heating and ventilation mechanical systems (HVAC)

\begin{tabular}{|c|c|c|c|c|c|}
\hline & & & HVAC_1 & HVAC _2 & HVAC_3 \\
\hline \multirow{3}{*}{ heating } & for $\boldsymbol{U} \boldsymbol{E}_{\mathbf{4 0}}$ & for $\boldsymbol{U} \boldsymbol{E}_{15}$ & \multirow{2}{*}{+} & & \\
\hline & radiator heating & surface heating & & & \\
\hline & surface heating & surface heating & & + & + \\
\hline \multirow{3}{*}{ ventilation } & natural & supply and exhaust, heat recovery $90 \%$ & + & & \\
\hline & supply and exhaust, heat recovery $60 \%$ & supply and exhaust, heat recovery $60 \%$ & & + & \\
\hline & supply and exhaust, heat recovery $80 \%$ & supply and exhaust, heat recovery $80 \%$ & & & + \\
\hline
\end{tabular}

Table 3

Analysed variants of energy sources - ES

\begin{tabular}{|l|l|c|c|c|c|c|c|}
\hline & & ES_1 & ES_2 & ES_3 & ES_4 & ES_5 & ES_6 \\
\hline \multirow{5}{*}{ basic source } & gas boiler (GCB) & + & & & & + & + \\
\cline { 2 - 8 } & district heating (DH) & & + & & & & \\
\cline { 2 - 8 } & ground heat pump (GHP) & & & + & & & \\
\cline { 2 - 8 } & bio-mass boiler (PB) & & & & + & & \\
\hline \multirow{2}{*}{ auxiliary source } & solar collectors (S) & & & & & + & \\
\cline { 2 - 8 } & photovoltaics (P) & & & & & & + \\
\hline
\end{tabular}

3.2. The investment costs. The initial costs were assumed by authors based on the analysis of the Polish consumer market in the 2016 year. These net costs were divided into construction and mechanical ones - permanent and independent from the variant (for BSC_1, $1887 \mathrm{PLN} / \mathrm{m}^{2}$, for BSC_3 - $1710 \mathrm{PLN} / \mathrm{m}^{2}$ ), the costs influencing the energy usage and the costs of the installed devices related to the energy consumption. The costs of application of supply-exhaust ventilation and the air inlets in the windows can be assigned to the last category.

The costs for the buildings, depending from the assumed grade of the heat recovery, are different and they are - for one-family building - from $127 \mathrm{PLN} / \mathrm{m}^{2}$ for heat recovery at the level of $60 \%$ to $152 \mathrm{PLN} / \mathrm{m}^{2}$ in case of $90 \%$ heat recovery; for the multi-family building those values are: from $99 \mathrm{PLN} / \mathrm{m}^{2}$ to $160 \mathrm{PLN} / \mathrm{m}^{2}$. These costs are only $5.1 \%$ (for BSC_1) or 5.4\% (for BSC_3) of the whole investment costs. The analyses include and paper presents the variability of the global costs values without the fixed investment (construction investment costs - building the envelope, plumbing the system, gas and electricity installations) costs.

\section{Application of methodology to select the optimal solution}

For such number of criteria the comparison was carried out by means of the weighted sum method [22], as the problem comes down to the optimization of more than one goal's function, but these functions can be contradictory.

4.1. Cost's optimal results. The global costs method is used in Poland and in many European countries to establish the requirements of thermal protection of the buildings [21, 23-33]. The 
(a)

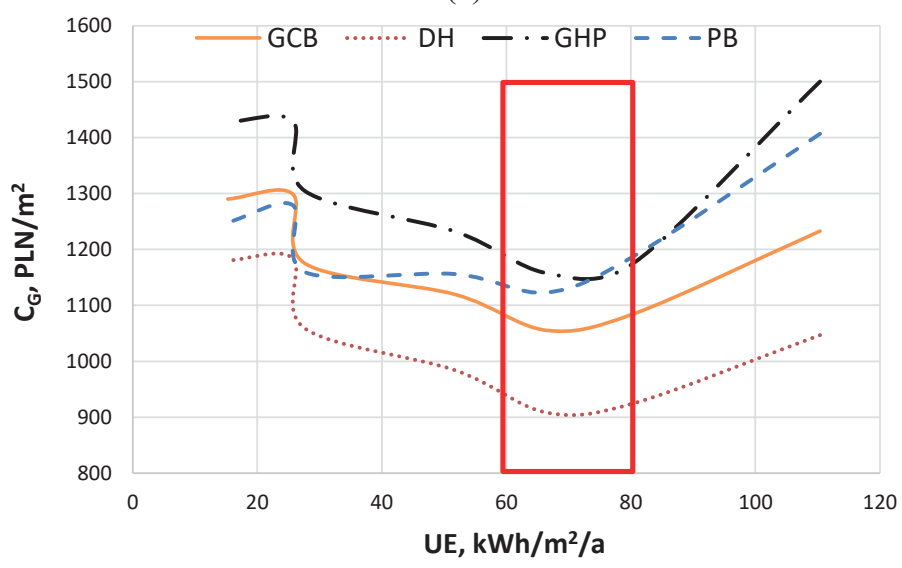

(b)

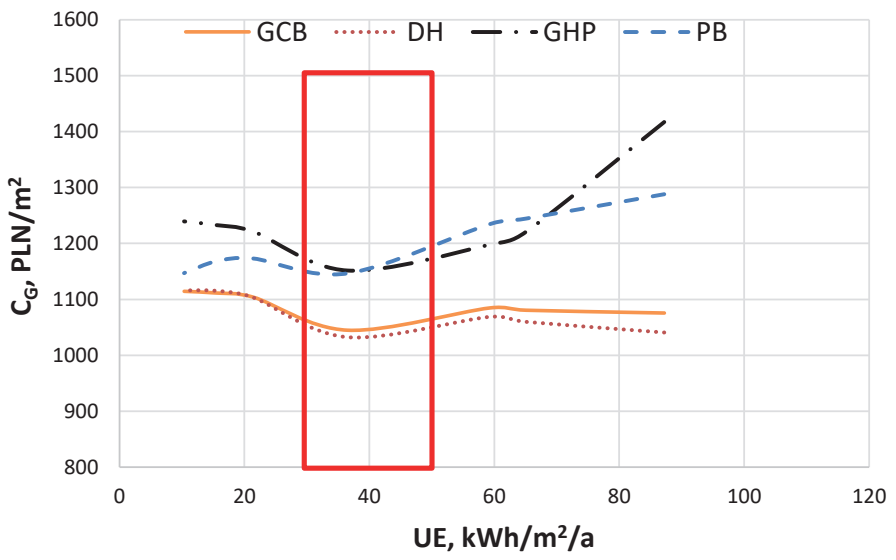

Fig. 2. The global costs for the analysed energy sources of the building of reference for variant values of the usable energy: a) BSC_1; b) BSC_3. Marking according to Table 3

analysis presented in the papers of Basińska et al. [21, 34, 35] shows that the optimal level (indicated by means of the global cost method) depends on a type of building and the assumed macro-economic parameters. For example (for macro-economic parameters and initial cost in 2016 year) at Fig. 2 it is presented, the level of optimal, in terms of the costs, technical solutions for the analysed buildings, taking under consideration Polish financial perspective (discount rate $=0.5 \%$, WIBOR $=1.80 \%$ ) and respectively, $2 \mathrm{a}-\mathrm{BSC} \_1$ building, $2 \mathrm{~b}-\mathrm{BSC} 3$ building. The analysis includes the variant application in the buildings the gas boiler (GCB), district heating (DH), ground heat pump (GHP) and bio-mass boiler (PB). For each of the analysed buildings $\mathrm{UE}_{15}$ standard lies beyond the area of optimal solutions (the space indicated by the red rectangular), taking into account the improvement of the thermal resistance of the buildings from base to very low energy building (VLEB) standard.

The energy-related optimum for one-family building lies in the area of the usable energy necessary for achieving the acceptable parameters of comfort and air quality at the level of $\mathrm{UE}=70 \mathrm{kWh} / \mathrm{m}^{2} / \mathrm{a}$, while in case of multi-family building $\mathrm{UE}=40 \mathrm{kWh} / \mathrm{m}^{2} / \mathrm{a}$. The bigger building is, the smaller is its shape index $(\mathrm{A} / \mathrm{V})$, the losses resulting from transmittance are getting lower and indoor gains are getting higher. In consequence the energy needed for maintaining the comfort and air quality parameters decreases.

When setting down $\mathrm{PE}_{\mathrm{opt}}$ the important are the assumed in the analysis the source of energy and the size of primary energy index for domestic hot water preparation [21, 34, 36]. Also significant is the way of installing the systems and the assumed level of the indoor gains [37].

For the analysed buildings only in case of bio-mass boiler application the energetic optimum, assumed by global cost method, lies in the area of the used energy at the level of $E_{15}$. The achievement of the given energy-related standard is possible through the application of the different activities. As mentioned in chapter 3 these activities can be classified as those connected to the building technique, the mechanical systems in terms of HVAC or the energy source, applied in the building.

Low energy building (LEB) - $\mathbf{U E}_{\mathbf{4 0}}$. By means of the global cost method the possible in the buildings, technical solutions were indicated, decreasing the global cost to the minimum in the area of the usable energy $\mathrm{UE}_{40}$.

The Fig. 3 (for BSC_1) and Fig. 4 (for BSC_3) are presenting the points with the coordinates $\left(\mathrm{PE} ; \mathrm{C}_{\mathrm{G}}\right)$ resulting from (a)

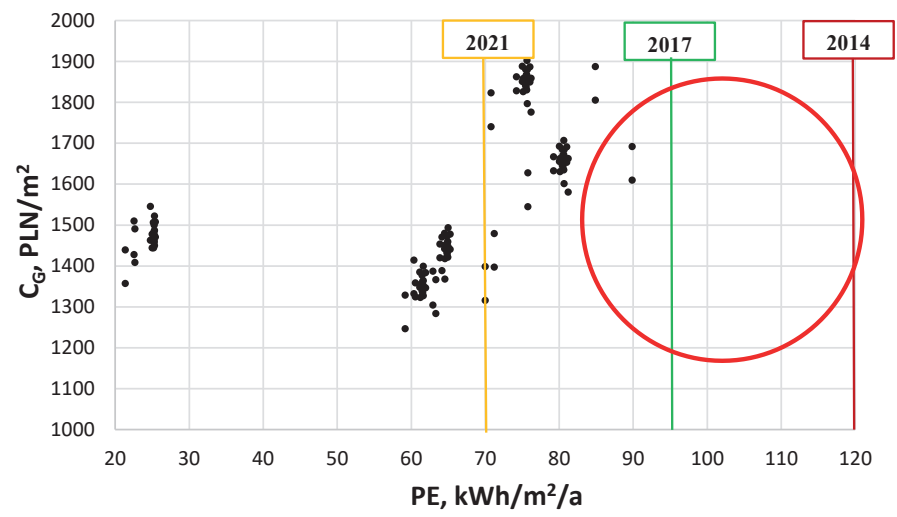

(b)

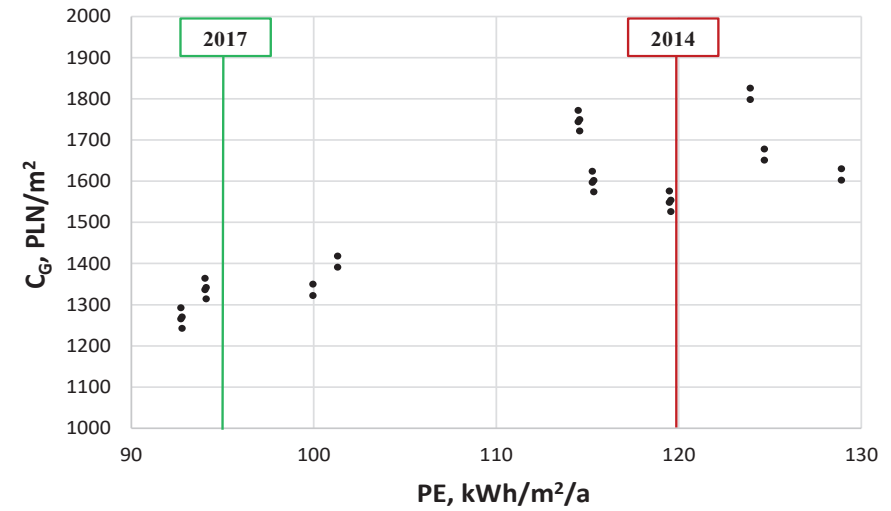

Fig. 3. The global costs for the analysed energy sources and reference building BSC_1 for $\mathrm{UE}_{40}$ : a) basic variants; b) zoom of the Fig. 3a supplemented by the variants with the corrected (in accordance with the valid thermal requirements) thickness of the insulation 
(a)

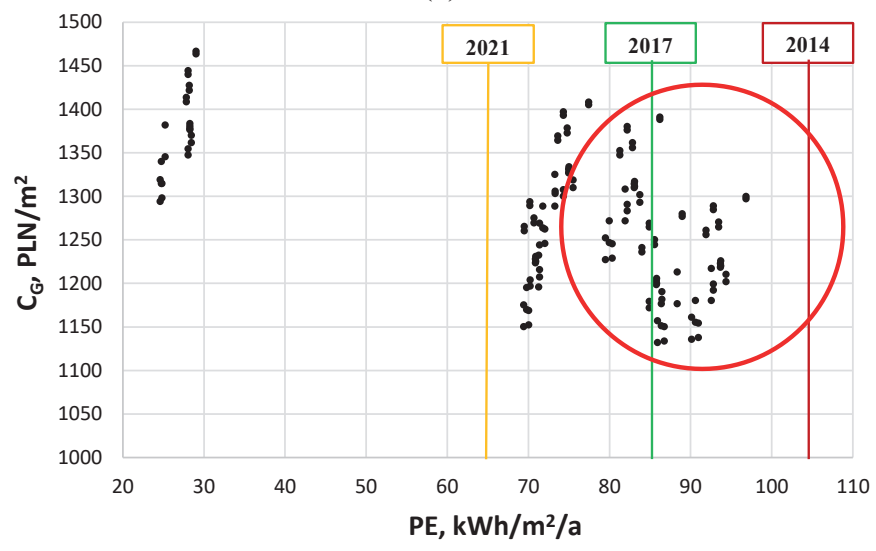

(b)

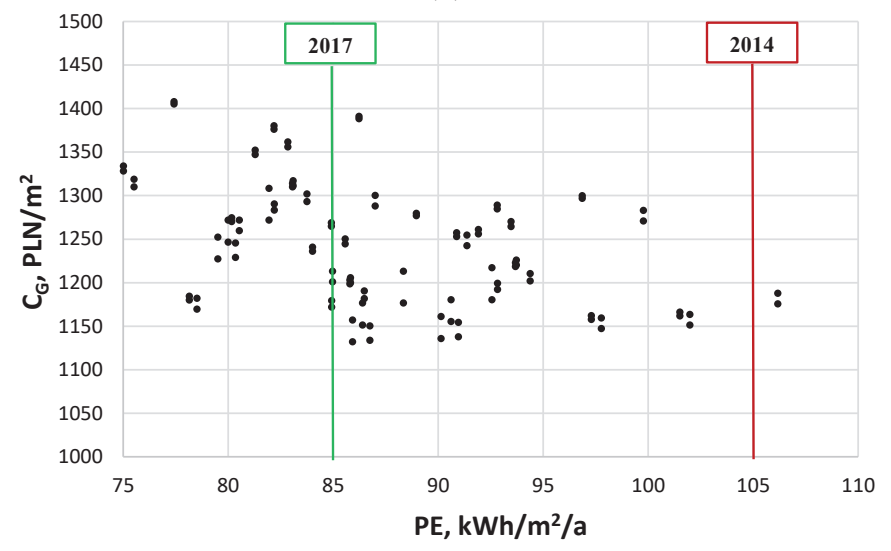

Fig. 4. The global costs for the analysed energy sources and reference building BSC_3 for $\mathrm{UE}_{40}$ : a) basic variants; b) zoom of the Fig. 4a supplements by the variants with the corrected (in accordance with the valid thermal requirements) thickness of the insulation

the combination of the construction activities (applied solution for the thermal insulation of the building partitions, the windows) or used different mechanical systems and the energy sources (HVAC, ES).

The Figs $3 \mathrm{a}$ and $4 \mathrm{a}$ are presenting two clouds of solution groups, depending on the energy source in the building. The cloud on the left refers to the solutions taking into account the usage of the bio-mass boiler.

The values of the primary energy are focusing at the level of $\mathrm{PE}=25 \mathrm{kWh} / \mathrm{m}^{2} / \mathrm{a}$ for BSC_1 building and $\mathrm{PE}=30 \mathrm{kWh} / \mathrm{m}^{2} / \mathrm{a}$ for BSC_ 3 building, what is influenced by the assumed value of the disbursement for non-renewable primary energy for biomass, $\mathrm{w}_{\mathrm{i}}=0.2[20]$.

For the multi-family building the variant with lowest value of the global cost, using the solution assuming the bio-mass boiler, is a variant (BE_2, HVAC_1) including the windows characterised by the heat transfer coefficient at the level $\mathrm{U}=1.8 \mathrm{~W} / \mathrm{m}^{2} / \mathrm{K}$, the thickness of thermal insulation of the external wall $\mathrm{d}_{\mathrm{izol}}=25 \mathrm{~cm}$, the air tightness equal $\mathrm{n}_{50}=1.5 \mathrm{~h}^{-1}$ and application of the natural ventilation in the building. For the one-family building - variant (BE_4, HVAC_1).

If to add, in the analysis for the gas boiler, the option of using energy coming from the photovoltaics, which covers $100 \%$ of auxiliary electric energy in the building (variant ES_6), it results in the decrease of value of the primary energy in that case. The raise of the global cost, as it will be necessary to assume in the analyses the investment costs related to the installation of the photovoltaic panels, covers the electric energy supply costs, assumed in the variant with gas boiler. For the variants not including the photovoltaic panels, in case of both buildings, the solution which generates the lower values of the global cost is the application of the natural ventilation and district heating, assuming the decrease of air tightness in the building, for BSC_1 - (BE_4, HVAC_1, ES_2), for BSC_3 - (BE_2, HVAC 1, ES_2).

The vertical lines on the diagram show the boundaries of the primary energy index defined in the state requirements (valid from 01.01.2014, then from 01.01.2017 and from 01.01.2021) [3]. These requirements in Poland depend from the type of building and do not depend on used energy source.

The analyses show that in order to achieve $\mathrm{UE}_{40}$ and the application natural ventilation in the building it is necessary to use the thermal insulation with the significant thickness at the building's envelope (until $50 \mathrm{~cm}$ of the insulation of the external wall). However there is some optimal thickness, above which the costs borne during production of the given thermo-insulating material are exceeding the savings, related to its application. So, the activities which are undertaken in order to increase significantly the thickness of thermal insulation should not be accepted. The assumption, made in analysis, in regards to the acceptable thickness of thermal insulation of the construction partitions (assumption of the heat transfer coefficient of the construction partitions at the level provided by the requirements for 2021) causes the decrease of the designed losses of the heat transmittance and also the relocation of the points in Figs. 3b and $4 \mathrm{~b}$ towards the higher value of the primary energy index $\left(\mathrm{UE}_{40} *\right)$.

It comes out, from the analysis of the presented diagrams, that in order to achieve the low energy standards for the buildings not only the works focused on the construction technology are needed but also the works connected to the mechanical systems (HVAC) are important. The above is particularly important if the task is to achieve the very low energy building (VLEB) standard $-\mathrm{UE}_{15}$.

Very low energy building (VLEB) - $\mathbf{U E}_{15}$. For assuring the low energy standard the control of the air flow in the building is necessary. The control can be gained only by an application of the supply - exhaust ventilation with heat recovery. In spite of the assumed grade of recovery the control of the airflow leads to the significant limitation of the ventilation heat losses element in the building's heat balance - and that leads to change of the proportion of the transmittance and ventilation losses. 
(a)

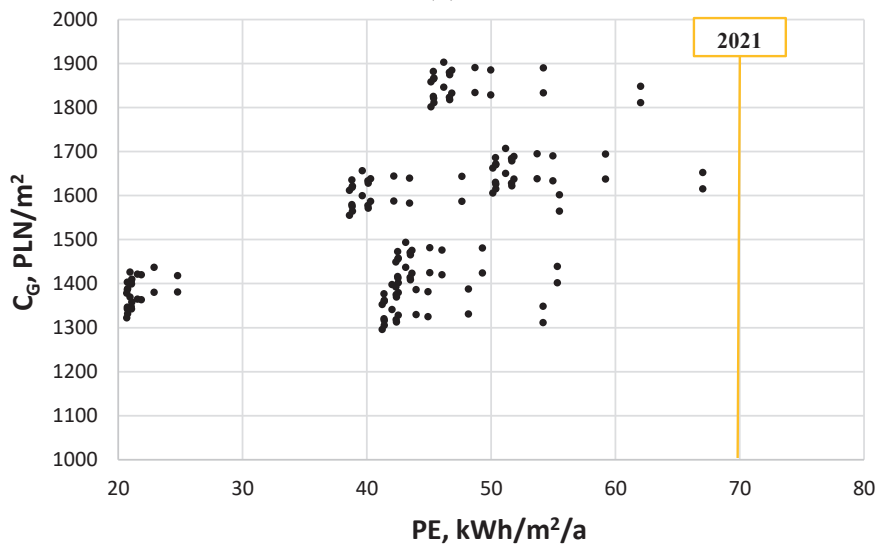

(b)

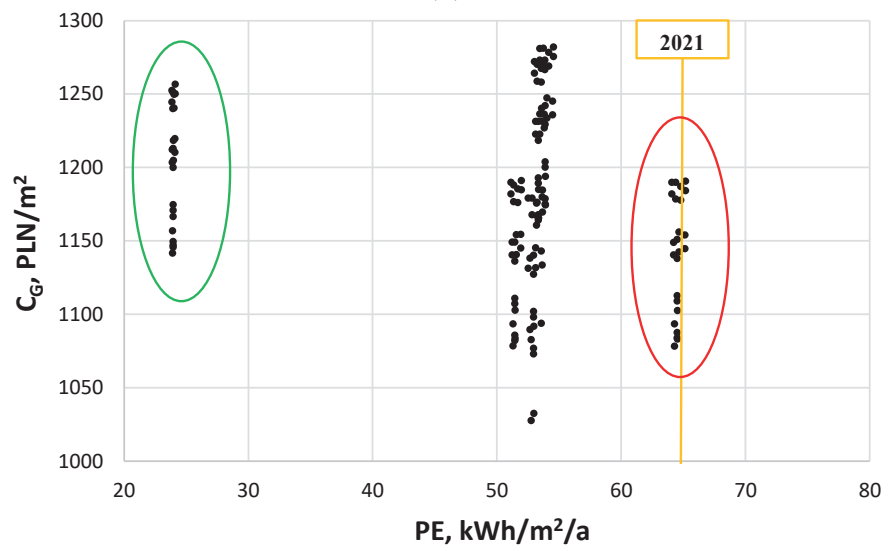

Fig. 5. The global costs for the analysed energy sources and the buildings for $\mathrm{UE}_{15}$ : a) BSC_1; b) BSC_3

Figure $5 \mathrm{~b}$ (for building BSC 3 ) presents 3 areas of the primary energy index variability for $\mathrm{UE}_{15}$. On the left side, the analyses were considering the bio-mass boiler, on the right side - gas boiler, in the middle - the remaining analysed solutions: gas boiler supported by the solar collector (for the purpose of the domestic hot water preparation), the gas boiler with the photovoltaic system, district heating and ground heat pump. For building BSC_1 (Fig. 5a) on the left side, the analyses were considering the bio-mass boiler. All analysed variants fulfil the requirements of building thermal protection for 2021 described by the maximum primary energy index for the one-family building at the level of $\mathrm{PE}=70 \mathrm{kWh} / \mathrm{m}^{2} / \mathrm{a}$, and for multi-family building $\mathrm{PE}=65 \mathrm{kWh} / \mathrm{m}^{2} / \mathrm{a}$.

4.2. Increase of investment costs. Based on the analysis of the Fig. 6 the Investor can decide and choose the optimal solution assuming the additional investment costs.

The investor will pay the lowest investment costs, in comparison with the basic solution, not including energy costs (for BSC_1 $-\mathrm{C}_{\mathrm{G}}{ }^{*}(\mathrm{BASE})=748 \mathrm{PLN} / \mathrm{m}^{2}$, BSC 3
$\left.-\mathrm{C}_{\mathrm{G}}{ }^{*}(\mathrm{BASE})=684 \mathrm{PLN} / \mathrm{m}^{2}\right)$ if he decides to implement the construction activities, to improve the building's air tightness and to install the windows characterised by the decreased the heat transfer coefficient.

On the other hand the highest cost can be expected if the supply-exhaust ventilation will be installed with a high-performance heat recovery or in case of application of the ground heat pump as energy source. However, every time the air quality in the building must be taken under consideration - this is possible, in case of the low energy buildings, only through the airflow control and heat recovery.

The global cost and the additional investments are shown in the diagram as a part of the current net value. The horizontal line reproduces the investment costs of the basic solution, not including the energy costs. It is clear that for all analysed variants the Investor has to take into account the decrease of the discounted investment costs in time.

4.3. Multi-criteria analysis. Analysing the building and its systems by means of the criteria being a subject of the sepa- (a)

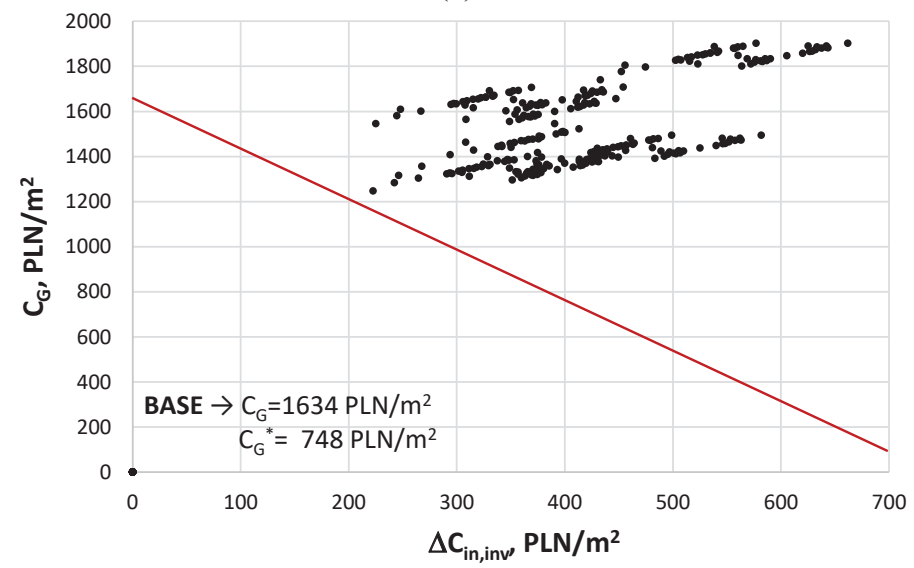

(b)

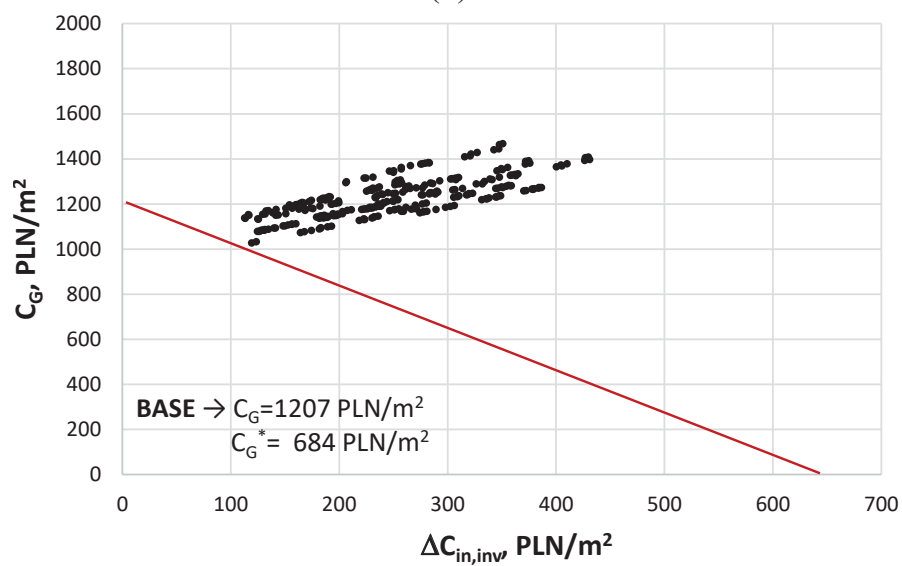

Fig. 6. The global costs and increase of the discounted investment costs in time until year zero in relation to the basic costs for variants $\mathrm{UE}_{15}$ and $\mathrm{UE}_{40}$ : a) $\mathrm{BSC}_{-}$; b) BSC_3 
rate analyses the different permissible solutions can be found [14-17, 38-43]. The multi-criteria analysis, proposed in this paper, allows for a classification of the alternative, technical solutions regarding HVAC systems and building itself designing taking under consideration: the economics, energy, environmental parameters in terms of complex energy-related optimum, keeping in the same time all limiting conditions. The technical possibilities to achieve $\mathrm{UE}_{40}$ and $\mathrm{UE}_{15}$ usage energy by the buildings, were analysed. The algorithms presented in Section 2, were applied in order to compare the assumed criteria.

To define the weight of the individual criterion the method presented in the paper of Mróz [22] were used. Method is based on statistical calculation of the deviation factor defined as the ratio of standard deviation of criterion $\rightarrow \mathbf{x}$ and its mean value. The weights of the individual criteria are changing depends on the analysed standards of energy for the considered buildings.

Table 4 presents the summary of the weights for the criteria and analysed energetic standards. The variant $\mathrm{UE}_{40} *$ is actu- ally $\mathrm{UE}_{40}$ where the solutions with maximum thickness of the thermal insulation (resulting from the maximum permissible the heat transfer coefficient) were added. As results from Table 4 the criterion with the highest weight is environmental, as it is important to EC policy due to fact that the greenhouse gases emission has to be limited by $20 \%$ until 2020 (comparing to the level in 1990). The criteria with the comparable weights are primary energy value and additional investment costs. The last ones seem to be the most important during taking the investment decisions by Investor. The presented results can be used as the auxiliary data for choosing the proper configuration of building systems, mechanical systems in terms of HVAC and the energy sources in the building. The method has allowed to search the appropriate system among the pre-defined alternatives. The final classification of the chosen solutions for $\mathrm{UE}_{40}$ and $\mathrm{UE}_{15}$ has been presented in the descending sequence in Table 5 for BSC_1, and in Table 6 for BSC_3 (no. 1 - the best variant, no. 8 - the worst one).

Table 4

Weights for the individual criteria

\begin{tabular}{|c|c|c|c|c|c|c|c|c|}
\hline \multicolumn{2}{|c|}{ Criterion r } & \multicolumn{4}{c|}{$\mathrm{r}=4$} & \multicolumn{3}{c|}{$\mathrm{r}=3$} \\
\hline Building & Considered criterion & $\mathbf{P E}$ & $\mathbf{C O}_{\mathbf{2}}$ & $\mathbf{C}_{\mathbf{G}}$ & $\Delta \mathbf{C}_{\text {in, inv }}$ & $\mathbf{P E}$ & $\mathbf{C}_{\mathbf{G}}$ & $\Delta \mathbf{C}_{\text {in, inv }}$ \\
\hline \multirow{2}{*}{ BSC_1 } & $\mathrm{UE}_{40}$ & 0.28 & 0.41 & 0.11 & 0.20 & 0.48 & 0.18 & 0.34 \\
\cline { 2 - 9 } & $\mathrm{UE}_{40}{ }^{*}$ & 0.28 & 0.41 & 0.08 & 0.23 & 0.47 & 0.14 & 0.39 \\
\cline { 2 - 10 } & $\mathrm{UE}_{15}$ & 0.26 & 0.41 & 0.12 & 0.21 & 0.45 & 0.20 & 0.35 \\
\hline \multirow{2}{*}{ BSC_3 } & $\mathrm{UE}_{40}$ & 0.27 & 0.39 & 0.06 & 0.29 & 0.44 & 0.09 & 0.47 \\
\cline { 2 - 9 } & $\mathrm{UE}_{40}{ }^{*}$ & 0.26 & 0.39 & 0.05 & 0.29 & 0.43 & 0.09 & 0.48 \\
\cline { 2 - 9 } & $\mathrm{UE}_{15}$ & 0.25 & 0.41 & 0.05 & 0.29 & 0.43 & 0.09 & 0.49 \\
\hline
\end{tabular}

Table 5

The final classification of the scenarios for building BSC_1

\begin{tabular}{|c|c|c|c|c|c|c|c|c|}
\hline UE & Scenario & $\mathrm{BE}$ & HVAC & ES & $\begin{array}{c}\text { PE, } \\
\mathrm{kWh} / \mathrm{m}^{2} / \mathrm{a}\end{array}$ & $\begin{array}{c}\mathbf{C O}_{2} \\
\mathrm{PLN} / \mathrm{m}^{2}\end{array}$ & $\begin{array}{c}\mathbf{C}_{\mathbf{G}}, \\
\mathrm{PLN} / \mathrm{m}^{2}\end{array}$ & $\begin{array}{l}\Delta \mathbf{C}_{\mathbf{i n}, \mathbf{i n v}}, \\
\mathrm{PLN} / \mathrm{m}^{2}\end{array}$ \\
\hline \multirow{8}{*}{$\mathbf{U} \mathbf{E}_{40}$} & 1 & 4 & 1 & 2 & 59 & 35 & 1246 & 223 \\
\hline & 2 & 2 & 1 & 2 & 63 & 38 & 1284 & 242 \\
\hline & 3 & 8 & 1 & 2 & 59 & 35 & 1329 & 305 \\
\hline & 4 & 3 & 1 & 2 & 63 & 38 & 1304 & 265 \\
\hline & 5 & 4 & 2 & 2 & 61 & 36 & 1325 & 296 \\
\hline & 6 & 2 & 3 & 2 & 61 & 37 & 1323 & 291 \\
\hline & 7 & 2 & 2 & 2 & 62 & 37 & 1327 & 294 \\
\hline & 8 & 4 & 3 & 2 & 62 & 37 & 1335 & 302 \\
\hline \multirow{8}{*}{$\mathbf{U E}_{15}$} & 1 & 1 & 3 & 6 & 39 & 15 & 1555 & 349 \\
\hline & 2 & 2 & 3 & 6 & 39 & 16 & 1564 & 358 \\
\hline & 3 & 1 & 1 & 6 & 39 & 16 & 1575 & 368 \\
\hline & 4 & 2 & 1 & 6 & 39 & 16 & 1579 & 372 \\
\hline & 5 & 1 & 2 & 6 & 40 & 16 & 1571 & 361 \\
\hline & 6 & 3 & 3 & 6 & 40 & 16 & 1577 & 367 \\
\hline & 7 & 3 & 1 & 6 & 40 & 16 & 1587 & 376 \\
\hline & 8 & 1 & 3 & 2 & 41 & 25 & 1296 & 351 \\
\hline
\end{tabular}


Table 6

The final classification of the scenarios for building BSC 3

\begin{tabular}{|c|c|c|c|c|c|c|c|c|}
\hline UE & Scenario & $\mathrm{BE}$ & HVAC & ES & $\begin{array}{c}\text { PE, } \\
\mathrm{kWh} / \mathrm{m}^{2} / \mathrm{a}\end{array}$ & $\begin{array}{c}\mathbf{C O}_{2} \\
\mathrm{PLN} / \mathrm{m}^{2}\end{array}$ & $\begin{array}{c}\mathbf{C}_{\mathbf{G}}, \\
\mathrm{PLN} / \mathrm{m}^{2}\end{array}$ & $\begin{array}{l}\Delta \mathbf{C}_{\text {in, inv }}, \\
\mathrm{PLN} / \mathrm{m}^{2}\end{array}$ \\
\hline \multirow{8}{*}{$\mathbf{U E}_{40}$} & 1 & 2 & 1 & 2 & 69 & 41 & 1150 & 801 \\
\hline & 2 & 4 & 1 & 2 & 70 & 42 & 1152 & 800 \\
\hline & 3 & 8 & 1 & 2 & 70 & 42 & 1169 & 817 \\
\hline & 4 & 3 & 1 & 2 & 70 & 42 & 1170 & 819 \\
\hline & 5 & 2 & 1 & 6 & 86 & 34 & 1132 & 810 \\
\hline & 6 & 6 & 1 & 2 & 69 & 41 & 1175 & 826 \\
\hline & 7 & 4 & 1 & 6 & 87 & 35 & 1134 & 809 \\
\hline & 8 & 2 & 1 & 1 & 90 & 37 & 1136 & 798 \\
\hline \multirow{8}{*}{$\mathbf{U E}_{15}$} & 1 & 1 & 2 & 6 & 53 & 21 & 1027 & 119 \\
\hline & 2 & 2 & 2 & 6 & 53 & 21 & 1032 & 124 \\
\hline & 3 & 3 & 2 & 6 & 53 & 21 & 1073 & 164 \\
\hline & 4 & 4 & 2 & 6 & 53 & 21 & 1077 & 168 \\
\hline & 5 & 5 & 2 & 6 & 53 & 21 & 1082 & 174 \\
\hline & 6 & 1 & 3 & 6 & 53 & 21 & 1090 & 182 \\
\hline & 7 & 6 & 2 & 6 & 53 & 21 & 1092 & 183 \\
\hline & 8 & 2 & 3 & 6 & 54 & 21 & 1094 & 183 \\
\hline
\end{tabular}

In case of each analysed building, for $\mathrm{UE}_{40}$ the optimal variants are the variants including the natural ventilation of the building with air tightness at the level of $1.5 \mathrm{~h}^{-1}$ and application in the building the radiator heating (apart from a number of assumed criteria). The most profitable option is to use the co-generations district heating or the condensation gas boiler with the photovoltaic cells covering the demands for auxiliary electric energy in the building. For VLEB buildings the share of electric energy coming from photovoltaics is crucial and such the solutions achieve the highest value of the weighted sum of the aggregated coefficients of the given variants. Apart from this solution the multi-criteria analysis indicated, for $\mathrm{UE}_{15}$ the optimal variants are the variants including styrofoam for wall insulation, the best windows, air tightness at the level of $1.0 \mathrm{~h}^{-1}$, application in the building the radiator heating and as energy sources - district heating. For BSC 1 building the heat recovery must be assumed at the level of $80 \%$, while in case of BSC_3 building $60 \%$ will be enough. Using the method described in this paper finding the proper solution is a simple task. For the defined preferences scenario, the method can support the designing and decision - taking process - leading to the best choice.

\section{Concluding remarks}

In this paper the multi-criteria method was used in the purpose of choosing the possible to apply technical solutions, which serve to improve the energy effectiveness of the building. Initially, it was proposed to use 144 solution packages to keep the usable energy in the building at the level of $\mathrm{UE}_{40}$ (LEB), then the packages where expended by 36 variants assuming the natural ventilation and heat transfer coefficient of the building partitions according to the regulations to be working in Poland from 2021. The analyses were carried out also for very low energy building standard (VLEB).

They cover the activities performed in the building as part of the construction works (BE), mechanical systems in terms of HVAC and applied energy source (ES).

The optimisation problem was solved by means of the weighted sum method.

The basic conclusions from multi-criteria optimization are summarized as follows:

1. The proposed model of multi-criteria optimization allows for classification of the alternative technical solutions regarding the designing of the building and HVAC systems, taking into account the criteria recognised as important ones.

2. The importance of criteria corresponds with the priorities not only of Designer but also User of the building and the State.

3. The choice of four criteria is not bonding, but it results from the rational energy-related and economic assumptions applied to the optimization process.

4. The proposed method of optimisation might be applied to support the designing of the building, its technical equipment and energy source.

5. The multi-variant optimisation along with the simplified tools of the energy-related evaluation of the building leads to a determination of the optimal solutions in the short calculation period.

6. The proposed model can be used not only for evaluation of HVAC systems but also for other structural and architectural solutions regarding the building's external partitions - both in newly built and existing objects. 
Based on the carried out analyses the following can be stated:

- In order to achieve $\mathrm{EU}_{40}$ energetic standard the natural ventilation can be applied only and exclusively in the buildings characterised by the very high thermal resistance of the building partitions (thickness of the insulation of the external wall above $30 \mathrm{~cm}$ for thermal conductivity of the level $0.037 \mathrm{~W} / \mathrm{m} / \mathrm{K})$.

- Assuming the value of usable energy as $\mathrm{EU}_{40}$ the fulfilling of the requirement regarding the thermal protection of the buildings, through primary energy index (PE) is possible only if the bio-mass heat source will be applied in the building.

- A biomass boiler can be used wherever it is not possible to use another energy source.

- For the Investor the final energy delivered to the building envelope is important, the low primary energy value, does not necessarily mean the low value of usable or final energy.

- The participation of the domestic hot water component increases in the buildings where low energy is used to maintain the comfort and air quality parameters; that participation is higher in the multi-family buildings than in the one-family buildings.

- The requirements regarding the building's thermal protection to be implemented on 2021 can be fulfilled only if the building will be equipped with high performance heat recovery or the renewable energy sources.

- It is difficult to achieve $\mathrm{UE}_{15}$ standard in one - family building where heat recovery in ventilation system is on the level of $60 \%$.

- In case of the low energy buildings it is important to evaluate the object, its technical equipment and its mechanical system (HVAC), in the same time.

- In order to limit the distribution losses HVAC systems should be decentralized - it is particularly important for low (LEB) and very low energy (VLEB) buildings.

- The importance of the mechanical systems (HVAC) increases in the low energy standard buildings. Their typology shall be adequate to the system.

- If HVAC system is not considered the evaluation of the building is incomplete and doubtful - in particular for VLEB buildings, where RES application is a necessity.

- The application of the renewable energy sources improves the energy-related characteristic of the building (PE).

- Investor knowing the additional costs related to achievement of the given energy standard in relations to the base standard might choose, by means of the global cost method, the technical solution whose costs will be fully acceptable. Summarising, it can be stated that in the low energy buildings (LEB, VLEB) in order to improve the performance of the systems securing the task functions in terms of accepted level of air quality, one shall strive to the optimisation of the energy usage, delivered to the object's balance protection by means of: the proper choice of technical systems, recovery of the heat energy, energy-optimal process control, and that optimisation should be performed by means of building's heating and cooling loads minimization, what in the effect leads to maintaining the exploitation costs at the rationally low level. Every time the investment costs, which shall be kept on the low level, must be taken into account. The decisive criterion for the state policy is $\mathrm{CO}_{2}$ emission.

\section{REFERENCES}

[1] The recast of the Energy Performance of Buildings Directive 2010/31/UE of 19 May 2010.

[2] Journal of Orders 290 dated 9.02.2016. Announcement of Polish Sejm's Speaker regarding the Order's unified text - The Building Law [in Polish].

[3] Journal of Orders 75, item 690 dated 12.02.2016. Order of Minister of Infrastructure regarding the technical conditions for the buildings and its location, as amended. [in Polish].

[4] PN EN ISO 13790. Energy performance of buildings. Calculation of energy use for space heating and cooling.

[5] Website of the Ministry of Infrastructure and Construction, http:// www.mib.gov.pl, access 3.01.2017.

[6] EU Energy, Transport and GHG Emissions Trends to 2050. Reference scenario, Luxembourg, Publications Office of the European Union, 2013.

[7] Energy Regulatory Office, http://www.ure.gov.pl, access 3.01.2017.

[8] Website of Veolia Poland, http://www.veolia.pl, access 3.01.2017.

[9] PN EN 15459. Energy performance of buildings. Economic word splitting procedure for energy systems in buildings.

[10] The National Centre for Emissions Management (KOBiZE). Word splitting Values (WO) and $\mathrm{CO}_{2}$ emission indicators (WE) for 2013 for Common Effective Emission Reporting for 2016, Warszawa, 2015 [in Polish].

[11] The National Centre for Emissions Management (KOBiZE). $\mathrm{CO}_{2}$ emission factors for the electric power at the final recipients for 2014 [in Polish].

[12] M. Airaksinen and P. Matilainen, "A carbon footprint of an office building" Energies 4, 1197-1210, 2011.

[13] C.A. Balaras, K. Droutsa, E. Dascalaki, and S. Kontoyiannidis, "Heating energy consumption and resulting environmental impact of European apartment buildings", Energ Buildings 37, 429-442, 2005.

[14] C. Diakaki, E. Grigoroudis, N. Kabelis, D. Kolokotsa, K. Kalaitzakis, and G. Stavrakakis, "A multi-objective decision model for the improvement of energy efficiency in buildings", Energy 35, 5483-5496, 2010.

[15] M. Fesanghary, S. Asadi, and Z.W. Geem, "Design of low-emission and energy-efficient residential buildings using a multi-objective optimization algorithm", Build Environ 49, 245-250, 2012.

[16] M. Hamdy, A. Hasan, and K. Siren, "Applying a multi-objective optimization approach for design of low-emission cost-effective dwellings", Build Environ 46, 109-123, 2011.

[17] J. Lizana, Á. Barrios-Padura, M. Molina-Huelva, and R. Chacartegui, "Multi-criteria assessment for the effective decision management in residential energy retrofitting", Energ Buildings 129, 284-307, 2016.

[18] J.J. Wang, Y.Y. Jing, C.F. Zhang, and J.H. Zhao, "Review on multi-criteria decision analysis aid in sustainable energy decision-making, Renew sust. Energ Rev 13, 2263-2278, 2009.

[19] T. Witkowski, P. Antczak, and A. Antczak, "Multi-objective decision making and search space for the evaluation of production process scheduling", Bull. Pol. Ac.: Tech. 57 (3), 195-208, (2009). 
[20] Journal of Orders 376 dated 27.02.2015. Regulation of the Minister of Infrastructure and Development on a methodology for determining the energy performance of a building or part of a building and energy performance certificate [in Polish].

[21] M. Basińska, H. Koczyk, and E. Szczechowiak, "Sensitivity analysis of determining the optimum energy for residential buildings in Polish conditions", Energ Buildings 107, 307-318, 2015.

[22] T.M. Mróz, Energy management in built environment. Tools and evaluation procedures, Poznan University of Technology, Poznań, 2013.

[23] C. Baglivo, P.M. Congedo, D. D'Agostino, and I. Zaca, "Cost-optimal analysis and technical comparison between standard and high efficient mono-residential buildings in a warm climate", Energy 83, 560-575, 2015.

[24] M. Ferrara, E. Fabrizio, J.Virgone, and M. Filippi, "A simulation-based optimization method for cost-optimal analysis of nearly Zero Energy Buildings", Energ Buildings 84, 442-457, 2014.

[25] L. Georges, C. Massart, G. VanMoeseke, and A. De Herde, "Environmental and economic performance of heating systems for energy-efficient dwellings: Case of passive and low-energy single-family houses", Energy Policy 40, 452-464, 2012.

[26] R. Geryło, "Energy-related conditions and envelope properties for sustainable buildings". Bull. Pol. Ac.: Tech. 64 (4), 697-707, (2016).

[27] R. Geryło, "The economic optimum of energy requirements for buildings in Poland", 61-th Scientific Conference of the Civil and Water Engineering of the Polish Academy of Science (PAN) and of the Science Committee PZITB, Bydgoszcz - Krynica, Problem part: Energy-saving construction in Poland - current state and perspectives, 2015 [in Polish].

[28] M. Hamdy, A. Hasan, and K. Siren, "A multi-stage optimization method for cost-optimal and nearly-zero-energy building solutions in line with the EPBD. Recast 2010", Energ Buildings 56, 189-203, 2013.

[29] H. Koczyk and M. Basińska, "Energy - economic optimum of installation solutions for energy efficient buildings", 61-th Scientific Conference of the Civil and Water Engineering of the Polish Academy of Science (PAN) and of the Science Committee PZITB, Bydgoszcz - Krynica, Problem part: Energy-saving construction in Poland - current state and perspectives, 2015 [in Polish].
[30] V.P. Shah, D.C. Debella, and R.J. Ries, "Life cycle assessment of residential heating and cooling systems in four regions in the United States", Energ Buildings 40, 503-513, 2008.

[31] S.F. Tadeu, R.F. Alexandre, A.J.B. Tadeu, C.H. Antunes, N.A.V. Simões, and P. Pereira da Silva, "A comparison between cost optimality and return on investment for energy retrofit in buildings. A real options perspective", Sustainable Cities and Society, 21, 12-25, 2016.

[32] The European Commission's website. https://ec.europa.eu/energy/en/topics/energy-efficiency/buildings, access 19.04.2017.

[33] W. Tian, "A review of sensitivity analysis methods in building energy analysis", Renew Sust. Energ Rev 20, 411-419, 2013.

[34] M. Basińska and H. Koczyk, "Analysis of the possibilities to achieve the low energy residential buildings standards", Technol Econ Dev Eco 22(6), 830-849, 2016.

[35] M. Basińska, H. Koczyk, and A. Kosmowski, "Assessment of thermo modernization using the global cost method", Energy Proced. 78, 2040-2045, 2015.

[36] W. Szaflik, "Hot water system's design in residential buildings", INSTAL, Warszawa, 2011 [in Polish].

[37] M. Basińska and H. Koczyk, „Impact of initial assumptions for assessment of apartment building using global cost method", Rynek Instalacyjny, 3, 53-56, 2015 [in Polish].

[38] A. Avgelis and A.M. Papadopoulos, "Application of multicriteria analysis in designing HVAC systems", Energ Buildings 41, 774-780, 2009.

[39] S.M. Bambrook, A.B. Sproul, and D. Jacob, "Design optimisation for a low energy home in Sydney", Energ Buildings 43, 1702-1711, 2011.

[40] K. Heikkila, "Environmental impact assessment using a weighting method for alternative air-conditioning systems", Build Environ 39, 1133-1140, 2004.

[41] C.J. Hopfe, G.L. Augenbroe, and J.L. Hensen, "Multi-criteria decision making under uncertainty in building performance assessment", Build Environ 69, 81-90, 2013.

[42] A.T. Nguyen, S. Reiter, and P. Rigo, "A review on simulation-based optimization methods applied to building performance analysis", Appl Energ 113, 1043-1058, 2014.

[43] K. Negendahl and T.R. Nielsen, "Building energy optimization in the early design stages: A simplified method", Energ Buildings 105, 88-99, 2015. 